\title{
The Relationship Between the Sport-Confidence and the Coach-Athlete Relationship in Student-Athletes
}

\author{
Eylem Gencer ${ }^{1}$, Arda Öztürk ${ }^{2}$ \\ ${ }^{1}$ School of Physical Education and Sports, Kirsehir Ahi Evran University, Kirsehir, Turkey \\ ${ }^{2}$ School of Physical Education and Sports, Harran University, Sanliurfa, Turkey \\ Correspondence: Eylem Gencer, School of Physical Education and Sports, Ahi Evran University, Kirsehir, Turkey. \\ E-mail: eylemgencer@gmail.com
}

Received: June 25, 2018

doi:10.11114/jets.v6i10.3388
Accepted: July 17, $2018 \quad$ Online Published: July 19, 2018

URL: https://doi.org/10.11114/jets.v6i10.3388

\begin{abstract}
The aim of this study was to examine the relationship between the sport-confidence and the coach-athlete relationship in Turkish national male student-wrestlers, and to investigate whether educational status, wrestling style, wrestling category, and career of wrestlers were significant variables on student-wrestlers' sport confidence and their relationship with their coaches. Participants were 198 Turkish national male wrestlers. Demographic questions, the Sport-Confidence Inventory (Vealey, 1986), and the Coach Athlete Relationship Questionnaire (Jowett \& Ntoumanis, 2004) were performed for data collection. Results indicated that sport-confidence was significantly related to coach-athlete relationship and sport-confidence was significant predictor of wrestlers' relationship with their coaches. Besides, wrestling style and wrestling category were significant variables on coach-athlete relationship. However, educational status and career of wrestlers were not significant variables in terms of sport-confidence and coach-athlete relationship. In conclusion, the findings of the study highlight that the association of sport-confidence and coach-athlete relationship can contribute to the understanding of relational process in sport.
\end{abstract}

Keywords: sport-confidence, coach-athlete relationship, educational status, elite wrestler

\section{Introduction}

Coach-athlete relationship is defined as interpersonal relationship where the emotions, thoughts, and behaviors of the coach and the athlete are causally and mutually interconnected (Jowett \& Ntoumanis, 2004; Adie \& Jowett, 2010; Isoard-Gautheur, Touilloud, Gustafsson \& Guillet-Descas, 2016). The coach-athlete relationship was separated into three dimensions that reflect these interconnected emotions, thoughts, and behaviors as closeness, commitment, and complementarity. Closeness is defined as feeling emotionally close in the coach-athlete relationship; it reflects mutual trust, respect and appreciation, as well as a predilection towards liking one another. Commitment is characterized by the intention to maintain a long-term athletic partnership. Complementarity refers to complementary or cooperative coach-athlete interactions. These dimensions are considered to be indicators of the quality of the coach-athlete relationship (Isoard-Gautheur et al., 2016).

It was stated as important by Jowett and Ntoumanis (2004) to examine antecedents and outcomes, as well as moderating and mediating variables of the coach-athlete relationship. Besides, the effect of coach-athlete relationship on motivational levels, performance, attrition, burnout, and confidence levels or vice versa was suggested for next researches for the coach-athlete relationship to be understood in an integrated approach.

The coach-athlete relationship construct has been examined within years in terms of performance (Rhind \& Jowett, 2010; Jowett \& Nezlek, 2012; Sagar \& Jowett, 2012; Jowett \& Cramer, 2009), collective efficacy (Hampson \& Jowett, 2014), motivational dispositions (Adie \& Jowett, 2010; Riley \& Smith, 2011; Jowett et al., 2017), well-being (Blanchard, Amiot, Perreault, Vallerant \& Provencher, 2009; Felton \& Jowett, 2013; Davis \& Jowett, 2014; Jowett \& Cramer, 2009), personality traits (Yang, Jowett \& Chan, 2015), need satisfaction (Choi, Cho \& Huh, 2013; Felton \& Jowett, 2013; Riley \& Smith, 2011), burnout (Isoard-Gautheur et al., 2016), personal growth (Sanchez, Lorenzo, Jimenez \& Lorenzo, 2017), passion ( Lafrenière, Jowett, Vallerand, Donahue \& Larimer, 2008; Lafrenière, Jowett, Vallerand \& Carbonneau, 2011), stress (Thelwell, Wagstaff, Chapman \& Kenttä, 2017), self-efficacy (Jackson, Grove \& Beauchamp, 2010). However, it is seen that the coach-athlete relationship and confidence has not been examined relationally. 
Sport-confidence concept that has been adapted by Vealey (1986) to measure sport-specific self-confidence originated from the constructs of self-efficacy (Bandura, 1977), perceived competence (Harter, 1978), and performance expectancy (Corbin, 1981) has been defined as the belief or degree of certainty individuals possess about their ability to be successful in sport. Sport-confidence concept has been separated into two dimensions as trait sport-confidence (SC-trait) that is the belief or degree of certainty individuals usually possess about their ability to be successful in sport, and state sport-confidence (SC- state) that is the belief or degree of certainty individuals at one particular moment possess about their ability to be successful in sport (Vealey, 1986). Self-efficacy beliefs that are the source of confidence are stated to be determinants of individuals' feelings, thoughts, motivation sources, and important mediator of all types of behavior (Pajares, 1997). Sport-confidence that was conceptualized to predict achievement behavior in sport environment (Vealey, 1986) has been the research interest of sport psychology. Self-confidence of athletes is enhanced when they achieve their goals, engage in effective self-regulation of cognitions and behavior and train and compete in a competitive climate that is supportive, challenging, comfortable and motivating (Vealey, Garner-Holman, Hayashi \& Giacobbi, 1998). The competitive climate here was stated as positive and achievement-nurturing climate which includes the sources of social support, coaches' leadership, vicarious experience, environmental comfort and situational favorableness.

Several researches have been examined on sport-confidence in sport context. Results revealed that self-confidence was predictor of performance (Jones, Swain \& Hardy, 1993; Jones, Hanton \& Connaughton, 2002; Craft, Magyar, Becker \& Feltz, 2003; Hays, Thomas, Maynard \& Bawden, 2009). Besides, high anxiety situations could be more easily coped with when having high confidence (Hardy, Jones \& Gould, 1996) and in the absence of self-confidence, increases in competitive anxiety intensity debilitated performance (Hanton, Mellalieu \& Hall, 2004). Furthermore, sport-confidence was related to experience (Comeig, Grau-Grau, Jaramillo-Gutierrez \& Ramirez, 2016), motivational dispositions (Magyar \& Feltz, 2003), peer interaction (Hwang, Machida \& Choi, 2017) locus of control, optimism and well-being (Şar \& Işıklar, 2012), and self-efficacy (Bozkurt, Koruç, Arslan \& Kocaekşi, 2012).

As seen in research studies, coach-athlete relationship and sport-confidence concepts have many things in common. For example, both the coach-athlete relationship and the sport-confidence are related to some variables such as performance, motivational dispositions, and well-being. In this respect, it can be expected that both structures are related to each other. Besides, it can be considered that there is a relationship between the coach athlete relationship and the sport-confidence, because motivational climate is expressed as a structure formed by the attitudes and behaviors of the coaches (Ames, 1992). When the literature is examined, the relation between the coach-athlete relationship and the sport-confidence, which are important determinants of performance, have not been examined relationally and which concept can predict the other has not been investigated. With this research, this relationship can be exhibited, and the concepts of coach athlete relationship and sport confidence can be understood in an integrated and relational approach.

\section{Method}

\subsection{Participants}

Participants were 198 Turkish national male wrestlers whose mean age was 20,02 ( $\mathrm{SD}=4,50)$ and career average was 9,14 years $(\mathrm{SD}=4,39)$. Participants wrestle in two different styles (Freestyle N=89, Greco-Roman style N=109). 119 wrestlers' educational status was high school and 79 wrestlers' educational status was university. Participants wrestle in three categories (Cadet N=79, Junior N=50, Senior N=69). Demographic features of wrestlers have been presented in table 1.

Table 1. Demographic features of participants.

\begin{tabular}{|c|c|c|c|c|}
\hline & & $\mathbf{N}$ & Mean & Sd \\
\hline Age & & 198 & 20.02 & 4.50 \\
\hline Career & & 198 & 9.14 & 4.39 \\
\hline \multirow[b]{2}{*}{ Style } & Freestyle & 89 & & \\
\hline & Greco-roman & 109 & & \\
\hline \multirow[b]{2}{*}{ Educational status } & High school & 119 & & \\
\hline & University & 79 & & \\
\hline \multirow{3}{*}{ Category } & Cadet & 79 & & \\
\hline & Junior & 50 & & \\
\hline & Senior & 69 & & \\
\hline
\end{tabular}

\subsection{Precedure}

Wrestling national team camps are set up separately in terms of categories and styles in different dates. Therefore, wrestlers were reached at national team camps on different dates for each category and styles (e.g., freestyle-cadet, greco-roman-cadet). The purpose and the content of the investigation were explained to athletes. Each participant who consented to participate was supplied a questionnaire. Questionnaire contained demographic questions (e.g., age, style, category, career), the Sport-Confidence Inventory (Vealey, 1986), and the Coach-Athlete Relationship Questionnaire (Jowett \& Ntoumanis, 2004). Following the instructions supplied by the researcher, participants completed the questionnaire independently. 


\subsection{Instruments}

\subsubsection{Sport-Confidence Inventory}

Sport-Confidence Inventory was developed by Vealey (1986) in two dimensions as Trait Sport-Confidence Inventory (TSCI) and State Sport-Confidence Inventory (SSCI), and adapted to Turkish by Engür, Tok and Tatar (2005). In this research Trait Sport-Confidence Inventory was used for data collection. The overall internal consistency coefficient of the trait sport-confidence was reported as 0,91. TSCI composes of 13 items that only measure sport specific self-confidence and ask subject to rate how confident they generally feel when competing in sports. A 9-point Likert scale that ranges from 1 (low) to 9 (high) was used for each item.

\subsubsection{Coach-Athlete Relationship Questionnaire}

The Coach-Athlete Relationship Questionnaire (CART-Q) that was developed by Jowett and Ntoumanis (2004) and adapted to Turkish by Altıntaş, Kazak Çetinkalp and Aşçı (2012) was used to assess the athletes' perceptions of the quality of the relationship with their coach. Internal consistency coefficients were reported to range from 0,82 to 0,90 for athletes and Turkish version of CART-Q was found acceptable to determine coach-athlete relationship. The CART-Q measures athletes' direct perceptions of closeness (e.g., "I respect my coach"), commitment (e.g., "I am committed to my coach"), and complementarity (e.g., "When I am with my coach I am ready to do my best"). The items are rated on a 7-point response scale ranging from 1 (strongly disagree) to 7 (strongly agree), with a mean of the 11-items being calculated to indicate the overall quality of the coach-athlete relationship. Higher scores indicated greater relationship quality in terms of closeness, commitment, and complementarity (3Cs).

\subsection{Data Analysis}

Analyses were performed by using SPSS (Version 20.0). Descriptive statistics including means, standard deviations, and bivariate correlation, linear regression, one-way anova, and independent-samples t-test were calculated for the study variables.

\section{Results}

Table 2. Relationship between sport-confidence and coach-athlete relationship.

\begin{tabular}{lllll}
\hline & & Closeness & Commitment & Complementarity \\
\hline \multirow{3}{*}{ Sport-Confidence } & Pearson correlation & .38 & .37 & .30 \\
& Sig. (2 tailed) & .00 & .00 & .00 \\
& $\mathrm{~N}$ & 198 & 198 & 198 \\
\hline
\end{tabular}

Associations between the sport-confidence and the coach-athlete relationship were analyzed by Bivariate Correlation. As seen in Table 2, sport-confidence of national male wrestlers is positively and significantly related to coach-athlete relationship (closeness $\mathrm{p}<0.01$; commitment $\mathrm{p}<0.01$; complementarity $\mathrm{p}<0.01$ ).

Table 3. Linear Regression Analysis on Predicting Coach-Athlete Relationship.

\begin{tabular}{llllll}
\hline Variable & B & Standart Error & Beta & t & p \\
\hline Constant & 3.05 & .48 & & 6.32 & .00 \\
Sport-confidence & 0.39 & .07 & .37 & 5.62 & .00 \\
\hline
\end{tabular}

$\mathrm{R}=0.37, \mathrm{R}^{2}=0.14, \mathrm{~F}(1,196)=31.53, \mathrm{p}=.00$

Table 3 presents the regression analysis of sport-confidence on predicting coach-athlete relationship. The result reveals that sport-confidence is a significant predictor of coach-athlete relationship $\left(\mathrm{R}=0.37, \mathrm{R}^{2}=0.14, \mathrm{~F}(1,196)=31.53, \mathrm{p}<\right.$ 0 .01) and it can be stated $14 \%$ of the total variance related to coach-athlete relationship is accounted by the sport-confidence.

Table 4. Comparison of sport-confidence and coach-athlete relationship of wrestlers in terms of wrestling styles.

\begin{tabular}{llllllll}
\hline & Style & $\mathbf{N}$ & Mean & Sd & df & t & Sig. \\
\hline Closeness & Freestyle & 89 & 6.32 & 1.03 & 196 & 4.24 & .00 \\
& Greco-Roman & 109 & 5.50 & 1.56 & & & \\
\hline Commitment & Freestyle & 89 & 5.83 & 1.16 & 196 & 2.66 & .00 \\
& Greco-Roman & 109 & 5.29 & 1.60 & & & \\
\hline \multirow{2}{*}{ Complementarity } & Freestyle & 89 & 5.94 & 1.02 & 196 & 2.49 & .01 \\
& Greco-Roman & 109 & 5.50 & 1.37 & & & \\
\hline Sport-Confidence & Freestyle & 89 & 7.11 & 1.20 & 196 & 1.86 & .06 \\
& Greco-Roman & 109 & 6.78 & 1.26 & & & \\
\hline
\end{tabular}

Table 4 presents the comparison of wrestling styles in terms of sport-confidence and coach-athlete relationship. Analyses were performed by Independent Samples T-Test. Results show that freestyle wrestlers' closeness, commitment, and complementarity scores are significantly higher than greco-roman style wrestlers' (closeness $\mathrm{p}<0.01$; commitment 
$\mathrm{p}<0.01$; complementarity $\mathrm{p}<0.05$ ). Although freestyle wrestlers' sport-confidence means are higher than greco-roman style wrestlers', it is not significantly higher $(\mathrm{p}>0.05)$.

Table 5. Comparison of sport-confidence and coach-athlete relationship of wrestlers in terms of educational status.

\begin{tabular}{llllllll}
\hline & Educational Status & N & Mean & Sd & df & t & Sig. \\
\hline Closeness & High school & 119 & 5.97 & 1.47 & 196 & 1.15 & .25 \\
& University & 79 & 5.73 & 1.31 & & & \\
\hline Commitment & High school & 119 & 5.61 & 1.50 & 196 & 0.87 & .38 \\
& University & 79 & 5.42 & 1.35 & & & \\
\hline Complementarity & High school & 119 & 5.74 & 1.30 & 196 & 0.60 & .54 \\
& University & 79 & 5.63 & 1.16 & & & \\
\hline \multirow{2}{*}{ Sport-Confidence } & High school & 119 & 6.84 & 1.30 & 196 & -1.19 & .23 \\
& University & 79 & 7.06 & 1.14 & & & \\
\hline
\end{tabular}

National male wrestlers' closeness, commitment, complementarity, and sport-confidence scores with regard to educational status were analyzed by Independent Samples T-test. Results demonstrate that wrestlers' closeness ( $\mathrm{p}>0.05)$, commitment ( $p>0.05)$, complementarity ( $p>0.05)$, and sport-confidence $(\mathrm{p}>0.05)$ scores do not differ from significantly in terms of educational status.

Table 6. Comparison of sport-confidence and coach-athlete relationship of wrestlers in terms of categories.

\begin{tabular}{llllllll}
\hline & Category & N & Mean & Sd & F & Sig. & Sig. Dif. \\
\hline \multirow{3}{*}{ Closeness } & Cadet & 79 & 6.18 & 1.35 & & & Cadet-Junior \\
& Junior & 50 & 5.52 & 1.50 & 3.72 & .02 & Cadet-Senior \\
& Senior & 69 & 5.77 & 1.35 & & & Junior-Senior \\
\hline \multirow{4}{*}{ Commitment } & Cadet & 79 & 5.85 & 1.32 & & & Cadet-Junior \\
& Junior & 50 & 5.16 & 1.60 & 3.80 & .02 & Cadet-Senior \\
& Senior & 69 & 5.44 & 1.39 & & & Junior-Senior \\
\hline \multirow{3}{*}{ Complementarity } & Cadet & 79 & 5.92 & 1.15 & & & \\
& Junior & 50 & 5.45 & 1.37 & 2.41 & .09 & \\
& Senior & 69 & 5.63 & 1.22 & & & \\
\multirow{3}{*}{ Sport-Confidence } & Cadet & 79 & 7.05 & 1.31 & & & \\
& Junior & 50 & 6.77 & 1.34 & .77 & .46 & \\
& Senior & 69 & 6.91 & 1.07 & & & \\
\hline
\end{tabular}

According to Table 6, sport-confidence and coach-athlete relationship of wrestlers in terms of categories were compared by One-Way Anova. Results put forward that there are significant differences between categories with regard to closeness $(\mathrm{p}<0.05)$ and commitment $(\mathrm{p}<0.05)$. To reveal which categories differ from others, Scheffe test was performed. Results show that the significant differences in both closeness and commitment are observed between the categories of cadet-junior, cadet-senior, junior-senior. However, the differences between the categories in terms of complementarity $(\mathrm{p}>0.05)$ and sport-confidence $(\mathrm{p}>0.05)$ are not significant.

Table 7. Relationship between career and coach-athlete relationship, sport-confidence.

\begin{tabular}{llllll}
\hline & & Closeness & Commitment & Complementarity & Sport-Confidence \\
\hline \multirow{4}{*}{ Career } & Correlation & -.12 & -.11 & -.08 & .03 \\
& Sig. & .11 & .12 & .28 & .72 \\
& $\mathrm{~N}$ & 198 & 198 & 198 & 198 \\
\hline
\end{tabular}

As can be seen in Table 7, the relationship between career and coach-athlete relationship, sport-confidence was analyzed by Bivariate Correlation. Results put forward that career of the wrestlers is not related to coach-athlete relationship (closeness $\mathrm{p}>0.05$; commitment $\mathrm{p}>0.05$; complementarity $\mathrm{p}>0.05$ ) and sport-confidence $(\mathrm{p}>0.05$ ) significantly.

\section{Discussion}

The aim of this study was to examine the relationship between the sport-confidence and coach-athlete relationship and also to find out whether sport-confidence and coach-athlete relationship were related to wrestling styles, educational status, wrestling categories, and career. The result revealed that sport-confidence of national male wrestlers was positively and significantly related to their relationship with their coaches. Besides, sport-confidence of wrestlers was found as a significant predictor of their relationship with their coaches. Furthermore, the freestyle wrestlers' closeness, commitment, and complementarity scores were significantly higher than the greco-roman style wrestlers'. Although the freestyle wrestlers' sport-confidence means were higher than the greco-roman style wrestlers', it was not significantly higher. Educational status of the wrestlers was not related significantly to their sport-confidence and relationship with their coaches. Categories of the wrestlers were significant variables in terms of closeness and commitment to their coaches. 
Finally, career of the wrestlers were not related significantly to their sport-confidence and relationship with their coaches.

Sport-confidence and coach-athlete relationship concepts that are related to performance have been examined several times as previously mentioned with regard to different constructs such as well-being, motivational dispositions, need satisfaction, anxiety, passion, etc. However, sport-confidence and coach-athlete relationship have not been investigated relationally. With this study, it was put forward that sport-confidence was significantly related to coach-athlete relationship and sport-confidence was significant predictor of athletes' relationship with their coaches. Thus, the results of the research will contribute to a better understanding of sport-confidence and coach-athlete relationship from a relational perspective. Whatever the sports branch is, the main goal is to be successful in all sports branches. When considered from this point of view, investigation of these two concepts that are so closely related to sport performance (Rhind \& Jowett, 2010; Jowett \& Nezlek, 2012; Sagar \& Jowett, 2012; Jowett \& Cramer, 2009; Jones et al., 1993; Jones et al., 2002; Craft et al., 2003; Hays et al., 2009) from different perspectives may also contribute to the practitioners in the field, and to the researchers who are doing theoretical and empirical work on the field. When the literature is examined, although there is not any research on the relationship between sport-confidence and coach-athlete relationship, it is possible to find some researches on coach-athlete relationship and well-being and self-efficacy that are related to sport-confidence with regard to meaning. For example, Felton and Jowett (2013) found that athletes' perceptions of satisfaction of basic psychological needs mediated the association between their attachment styles and well-being. Jowett and Cramer (2009) put forward that personal relationships were likely to contribute to athletes' overall well-being. Davis and Jowett (2014) found that coach-athlete relationship quality was related to well-being. Jackson, Grove and Beauchamp (2010) put forward that interpersonal relationship was related to self-efficacy.

Another result of the research reveals that the freestyle wrestlers' closeness and commitment to their coaches were greater than the greco-roman style wrestlers'. Freestyle wrestling is a traditional sport in Turkey. For example, "Kırkpınar" oil wrestling is a tradition of 656 years. Master-apprentice relationship is regarded as an integral part of this tradition and is still being kept alive. Furthermore, oil wrestling is performed in freestyle. The result that is in favor of freestyle wrestlers may be considered as an outcome of this tradition.

The closeness, commitment, complementarity, and sport-confidence of the wrestlers were examined with regard to their educational status. The results demonstrated that educational status was not a significant variable on coach-athlete relationship and sport-confidence. Öztürk, Bayazıt and Gencer (2016) similarly found that educational status was not a significant variable on sport-confidence.

In the research, the wrestlers' closeness and commitment scores differed in terms of categories. The categories of wrestling are formed according to age groups. Cadet wrestling category consists of wrestlers between the ages of 15-17. Junior wrestling category consists of wrestlers between the ages of 18-23 and, senior wrestling category consists of wrestlers above 23 years. The results obtained from the research showed that the cadet wrestlers' closeness and commitment scores were higher than the junior and senior wrestlers'. Besides, the senior wrestlers' closeness and commitment scores were higher than the junior wrestlers'. It is seen that wrestlers' closeness and commitment are greater in lower age groups. However, closeness and commitment scores decrease in middle age groups. On the contrary, closeness and commitment scores increase in upper age groups. It can be assumed that this result is due to age-related developmental periods. Nonetheless, this result may also be due to the different forms of relationship preferred by the coaches in different categories.

The last result of the study indicates that the career of the wrestlers was not a significant variable on coach-athlete relationship and sport confidence. Nevertheless, Comeig, Grau-Grau, Gutierrez and Ramirez (2016) put forward that experience in competitive sports was related to higher self-confidence. The research group in this study comprised of national wrestlers. In this respect, all the wrestlers are successful athletes in their branches. Thus, the reason why the sport-confidence of the wrestlers participated in this research did not differ in terms of career may be due to being consisted of the wrestlers whose self-confidence were already high. Similarly, Selağzı and Çepikkurt (2014) demonstrated athletes' relationship did not differ in terms of career.

In conclusion, sport-confidence and wrestlers' relationship with their coaches are related to each other. Sport-confidence is an important factor that affects wrestlers' relationship with their coaches. Moreover, the wrestling styles performed by wrestlers and wrestling categories that wrestlers take part in are the important variables in terms of their relationship with their coaches. Nevertheless, educational status and career of wrestlers are not important variables in terms of coach-athlete relationship. Lastly, sport-confidence of the wrestlers does not differ in terms of wrestling category, wrestling style, educational status, and career.

Finally, this study has some limitations. Research was conducted with national male wrestlers in Turkey. Sport-confidence and coach-athlete relationship of athletes may differ depending on the society they live in and the culture they have. In addition, examining the relation between sport-confidence and coach-athlete relationship in different sport branches may contribute to generalizability of the findings of the research. 


\section{References}

Adie, J. W., \& Jowett, S. (2010). Meta-perceptions of the coach-athlete relationship, achievement goals, and intrinsic motivation among sport participants. Journal of Applied Social Psychology,40(11), 2750-2773. https://doi.org/10.1111/j.1559-1816.2010.00679.x

Altıntaş, A., Çetinkalp, Z. K., \& Aşçı, F. H. (2012). Evaluating the Coach-Athlete Relationship: Validity and Reliability Study. Hacettepe Journal of Sport Sciences, 23(3), 119-128.

Ames, C. (1992). Achievement goals motivational climate, and motivational processes. In Roberts, G. C. (Ed.), Motivation in Sport and Exercise (pp. 161-176) . Champaign, Illinois: Human Kinetics.

Bandura, A. (1977). Self-efficacy: Toward a unifying theory of behavioral change. Psychological Review, 84(2), 191-215. https://doi.org/10.1037/0033-295X.84.2.191

Blanchard, C. M., Amiot, C. E., Perreault, S., Vallerand, R. J., \& Provencher, P. (2009). Cohesiveness, coach's interpersonal style and psychological needs: Their effects on self-determination and athletes' subjective well-being. Psychology of Sport and Exercise, 10(5), 546-551. https://doi.org/10.1016/j.psychsport.2009.02.005

Bozkurt, O., Koruç, Z., Arslan, N., \& Kocaekşi, S. (2012). A comparison of football players' sport confidence and self-efficacy beliefs according to their league level in Turkey. Nigde University Journal of Physical Education And Sport Sciences, 6(3), 349-356.

Choi, H., Cho, S., \& Huh, J. (2013). The Association Between the Perceived Coach-Athlete Relationship and Athletes' Basic Psychological Needs. Social Behavior \& Personality, 41(9), 1547-1556. https://doi.org/10.2224/sbp.2013.41.9.1547

Comeig, I., Grau-Grau, A., Jaramillo-Gutiérrez, A., \& Ramírez, F. (2016). Gender, self-confidence, sports, and preferences for competition. Journal of Business Research, 69, 1418-1422. https://doi.org/10.1016/j.jbusres.2015.10.118

Corbin, C. B. (1981). Sex of subject, sex of opponent, and opponent ability as factors affecting self-confidence in a competitive situation. Journal of Sport Psychology, 3, 265-270. https://doi.org/10.1123/jsp.3.4.265

Craft, L. L., Magyar, T. M., Becker, B. J., \& Feltz, D. (2003). The Relationship between the Competitive State Anxiety Inventory-2 and Sport Performance: A Meta-Analysis, Journal Of Sport \& Exercise Psychology, 25, 44-65. https://doi.org/10.1123/jsep.25.1.44

Davis, L., \& Jowett, S. (2014). Coach-athlete attachment and the quality of the coach-athlete relationship: implications for athlete's well-being. Journal of Sports Sciences, 32(15), 1454-1464. https://doi.org/10.1080/02640414.2014.898183

Engür, M., Tok, S., \& Tatar, A. (2005). Adaptation of State and Trait Sport Confidence Scales. Performans, 11(3), 7-12.

Felton, L., \& Jowett, S. (2013). "What do coaches do" and "how do they relate": Their effects on athletes' psychological needs and functioning. Scandinavian Journal of Medicine and Sports Sciences, 23, 130-139. https://doi.org/10.1111/sms.12029

Felton, L., \& Jowett, S. (2013). The mediating role of social environmental factors in the associations between attachment styles and basic needs satisfaction. Journal of Sport Sciences, 31(6), 618-628. https://doi.org/10.1080/02640414.2012.744078

Hampson, R., \& Jowett, S. (2014). Effects of Coach Leadership and Coach-Athlete Relationship on Collective Efficacy. Scandinavian Journal of Medicine \& Science in Sports, 24, 454-460. https://doi.org/10.1111/j.1600-0838.2012.01527.x

Hanton, S., Mellalieu, S. D., \& Hall, R. (2004). Self-confidence and anxiety interpretation: A qualitative investigation, Psychology of Sport and Exercise, 5(4), 477-495. https://doi.org/10.1016/S1469-0292(03)00040-2

Hardy, L., Jones, G., \& Gould, D. (1996). Understanding psychological preparation for sport: Theory and Practice of Elite Performers, New York: Wiley.

Harter, S. (1978). Effectance motivation reconsidered: Toward a developmental model. Human Development, 21, 34-64. https://doi.org/10.1159/000271574

Hays, K., Thomas, O., Maynard, I., \& Bawden, M. (2009). The role of confidence in world-class sport performance, Journal of Sports Sciences, 27(11), 1185-1199. https://doi.org/10.1080/02640410903089798

Hwang, S., Machida, M., \& Choi, Y. (2017). The effect of peer interaction on sport confidence and achievement goal orientation in youth sport. Social Behavior and Personality, 45(6), 1007-1018. https://doi.org/10.2224/sbp.6149 
Isoard-Gautheur, S., Trouilloud, D., Gustafsson, H., \& Guillet-Descas, E. (2016). Associations between the perceived quality of the coach-athlete relationship and athlete burnout: An examination of the mediating role of achievement goals. Psychology of Sport and Exercise, 22, 210-217. https://doi.org/10.1016/j.psychsport.2015.08.003

Jackson, B., Grove, J. R., \& Beauchamp, M. R. (2010). Relational efficacy beliefs and relationship quality withincoachathlete dyads. Journal of Social and Personal Relationships, 27(8), 1035-1050.

https://doi.org/10.1177/0265407510378123

Jones, G., Hanton, S., \& Connaughton, D. (2002). What is this thing called mental toughness? An investigation of elite sport performers, Journal of Applied Sport Psychology, 14(3), 205-218.

https://doi.org/10.1080/10413200290103509

Jones, G., Swain, A., \& Hardy, L. (1993). Intensity and direction dimensions of competitive state anxiety and relationships with performance. Journal of Sports Sciences, 11(6), 525-532. https://doi.org/10.1080/02640419308730023

Jowett, S. \& Nezlek, J. (2012). Relationship interdependence and satisfaction with important outcomes in coachathlete dyads. Journal of Social and Personal Relationships, 29(3), 287-301. https://doi.org/10.1177/0265407511420980

Jowett, S., \& Cramer, D. (2009). The role of romantic relationships on athletes' performance and well-being. Journal of Clinical Sports Psychology, 3, 58-72. https://doi.org/10.1123/jcsp.3.1.58

Jowett, S., \& Ntoumanis, N. (2004). The Coach - Athlete Relationship Questionnaire (CART - Q): Development and initial validation. Scandinavian Journal of Medicine \& Science in Sports, 14, 245-257. https://doi.org/10.1111/j.1600-0838.2003.00338.x

Jowett, S., Adie, J. W., Bartholomew, K. J., Yang, S. X., Gustafsson, H., \& Lopez-Jimenez, A. (2017). Motivational processes in the coach-athlete relationship: A multicultural self-determination approach. Psychology of Sport and Exercise, 32, 143-152. https://doi.org/10.1016/j.psychsport.2017.06.004

Lafrenière, M. A. K., Jowett, S., Vallerand, R. J., \& Carbonneau, N. (2011). Passion for coaching and the quality of the coach-athlete relationship: The mediating role of coaching behaviors. Psychology of Sport and Exercise, 12, 144-152. https://doi.org/10.1016/j.psychsport.2010.08.002

Lafrenière, M. A. K., Jowett, S., Vallerand, R. J., Donahue, E. G., \& Lorimer, R. (2008). Passion in sport: on the quality of the coach-athlete relationship. Journal of Sport \& Exercise Psychology, 30, 541-560. https://doi.org/10.1123/jsep.30.5.541

Magyar, T.M., \& Feltz, D.L. (2003). The influence of dispositional and situational tendencies on adolescent girls' sport confidence sources. Psychology of Sport and Exercise, 4, 175-190. https://doi.org/10.1016/S1469-0292(01)00037-1

Öztürk, A., Bayazit, B., \& Gencer, E. (2016). The Investigation of Judokas' Problem Solving Skills and Sport Confidence Levels (Trabzon Sample Center of Olympic Preparation). Spormetre Journal of Physical Education and Sport Sciences, 14 (2), 145-151.

Pajares, F. (1997). Current directions in self-efficacy research. In M. L. Maehr \& P. R. Pintrich (Eds.), Advances in motivation and achievement (Vol. 10, pp. 1-49). Greenwich, CT: JAI Press.

Rhind, D. A., \& Jowett, S. (2010). Initial evidence for the criterion-related and structural validity of the long versions of the coach-athlete relationship questionnaire. European Journal of Sport Science, 10, 359-370. https://doi.org/10.1080/17461391003699047

Riley, A., \& Smith, A. L. (2011). Perceived coach-athlete and peer relationships of young athletes and self-determined motivation for sport. International Journal of Sport Psychology, 42, 115-133.

Sagar, S. S., \& Jowett, S. (2012). Communicative Acts in Coach-Athlete Interactions: When Losing Competitions and When Making Mistakes in Training, Western Journal of Communication, 76(2), 148-174. https://doi.org/10.1080/10570314.2011.651256

Sanchez, J. M., Lorenzo, A., Jimenez, S. L., \& Lorenzo, J. (2017). The coach as youth players' mentor: study of positive coach-athlete relationships. Journal of Sport Psychology, 26(1), 95-99.

Şar, A. H., \& Işı1klar, A. (2012). Examination of locus of control, subjective well-being and optimism as the predictors of sport confidence. Nigde University Journal of Physical Education And Sport Sciences, 6(1), 76-84.

Selağzı, S., \& Çepikkurt, F. (2014). Determination of coach and athlete communication levels. CBU Journal of Physical 
Education and Sport Sciences, 9(1), 11-18.

Thelwell, R. C., Wagstaff, C. R. D., Chapman, M. T., \& Kenttä, G. (2017). Examining coaches’ perceptions of how their stress influences the coach-athlete relationship. Journal of Sports Sciences, 35(19), 1928-1939. https://doi.org/10.1080/02640414.2016.1241422

Vealey, R. S. (1986). Conceptualization of sport-confidence and competitive orientation: Preliminary investigation and instrument development. Journal of Sport Psychology, 8, 221-246. https://doi.org/10.1123/jsp.8.3.221

Vealey, R. S., Garner-Holman, M., Hayashi, S. W., \& Giacobbi, P. (1998). Sources of sport-confidence: Conceptualization and instrument development. Journal of Sport and Exercise psychology, 20(1), 54-80. https://doi.org/10.1123/jsep.20.1.54

Yang, X. S., Jowett, S., \& Chan, D. K. (2015). Effects of the big-five personality traits on the quality of relationship and satisfaction in coach-athlete dyads. Scandinavian Journal of Medicine and Sports Sciences, 25(4), 568-580. https://doi.org/10.1111/sms.12329

\section{Copyrights}

Copyright for this article is retained by the author(s), with first publication rights granted to the journal.

This is an open-access article distributed under the terms and conditions of the Creative Commons Attribution license which permits unrestricted use, distribution, and reproduction in any medium, provided the original work is properly cited. 